\title{
Genetic Variability of the Glucose-Dependent Insulinotropic Peptide Gene Is Involved in the Premature Coronary Artery Disease in a Chinese Population with Type 2 Diabetes
}

\author{
Xiaowei Ma $\mathbb{D}^{1},{ }^{1}$ Jia Huang, ${ }^{1}$ Difei Lu, ${ }^{1}$ Nan Gu, ${ }^{1}$ Ran Lu, ${ }^{2}$ Jianwei Zhang, ${ }^{1}$ Hong Zhang, \\ Jianping Li, ${ }^{3}$ Junqing Zhang, ${ }^{1}$ and Xiaohui Guo ${ }^{1}$ \\ ${ }^{1}$ Department of Endocrinology, Peking University First Hospital, Beijing, China \\ ${ }^{2}$ Department of Endocrinology, Peking University Third Hospital, Beijing, China \\ ${ }^{3}$ Department of Cardiology, Peking University First Hospital, Beijing, China \\ Correspondence should be addressed to Xiaowei Ma; mxiaowei1967@sina.com
}

Received 11 December 2017; Accepted 28 February 2018; Published 25 March 2018

Academic Editor: Carolina Baraldi Araujo Restini

Copyright (C) 2018 Xiaowei Ma et al. This is an open access article distributed under the Creative Commons Attribution License, which permits unrestricted use, distribution, and reproduction in any medium, provided the original work is properly cited.

\begin{abstract}
Background. Glucose-dependent insulinotropic polypeptide (GIP) is closely related to diabetes and obesity, both of which are confirmed to increase the risk of coronary artery disease (CAD). Our study aimed to investigate whether the polymorphisms in GIP genes could affect the risk of cardiovascular disease in type 2 diabetic patients in the Chinese Han population. Methods. We selected and genotyped two haplotype-tagging single nucleotide polymorphisms (tag-SNPs) (rs2291725 C>T, rs8078510 G>A) of GIP gene based on CHB data in HapMap Phase II database $\left(r^{2}<0.8\right)$. The case-control study of Chinese Han population involved 390 diabetic patients with CAD as positive group and 276 diabetic patients without CAD as control group. Allele and genotype frequencies were compared between the two groups. Results. In dominant inheritance model, the carriers of $\mathrm{T} / \mathrm{T}$ or $\mathrm{T} / \mathrm{C}$ had a lower risk of $\mathrm{CAD}(\mathrm{OR}=0.635,95 \% \mathrm{CI}=0.463-0.872, p=0.005)$, even after adjustment other $\mathrm{CAD}$ risk factors (gender, age, BMI, smoking status, dyslipidemia, hypertension history, and diabetic duration) $\left(\mathrm{OR}^{\prime}=0.769\right.$, $\left.95 \% \mathrm{CI}^{\prime}=0.626-0.945, p^{\prime}=0.013\right)$. The allele $\mathrm{A}$ at rs8078510 was associated with decreased risk of $\mathrm{CAD}(\mathrm{OR}=0.732$, $p=0.039) . p=0.018$ in subgroup analysis, individuals with higher BMI $\left(\geq 24 \mathrm{~kg} / \mathrm{m}^{2}\right)$ had increased risk for CAD when carrying $\mathrm{C} / \mathrm{C}$ at $\mathrm{rs} 2291725\left(\mathrm{OR}^{\prime}=1.291,95 \% \mathrm{CI}^{\prime}=1.017-1.639, p^{\prime}=0.036\right)$. In age $<55$ men and age $<65$ women, the carriers of allele $\mathrm{C}$ at rs2291725 had a higher risk of CAD than noncarriers $(\mathrm{OR}=1.627, p=0.015)$. Carriers of allele $\mathrm{G}$ in rs8078510 had higher susceptibility to CAD ( $\mathrm{OR}=2.049,95 \%=\mathrm{CI} 1.213-3.463, p=0.007) . p=0.004$; in addition, allele $\mathrm{G}$ in rs8078510 would bring higher CAD risk to the carriers who ever smoked $(\mathrm{OR}=1.695,95 \% \mathrm{CI}=1.080-2.660, p=0.021)$. Conclusion. The genetic variability of GIP gene is associated with CAD and it may play a role in the premature CAD in the Chinese Han population with type 2 diabetes.
\end{abstract}

\section{Introduction}

Glucose-dependent insulinotropic polypeptide (GIP), as an incretin, is synthesized and secreted by $\mathrm{K}$ cells of duodenum and jejunum, mainly after feeding, and then rapidly degradated by circular DPP-4 (dipeptidyl peptidase-4). GIP has the glucose-dependent insulinotropic effect by interacting with its receptor GIPR. It can also help increase the transcription of insulin gene and the expression of GLUT-1 (glucose transporter-1) and hexokinase-1 genes [1]. Besides, GIP improves the proliferation of pancreatic $\beta$ cells and prevents them from apoptosis [2-8]. At the level of fasting blood glucose (about $5.1 \mathrm{mmol} / \mathrm{L}$ ), GIP can promote the secretion of pancreatic glucagon and weaken the insulinotropic effect refraining from hypoglycemia. When the blood glucose reaches $6-7 \mathrm{mmol} / \mathrm{L}$, it has the opposite effect $[9,10]$.

In type 2 diabetic (T2D) patients, the GIP levels in blood are higher than normal people, but its insulinotropic effect is attenuated, which is called GIP resistance [11]. The GIP 
resistance impairs the glucose regulation and the stimulating effect on adipogenesis, which contributes to insulin resistance. GIP can also directly protect vessels from atherosclerosis. Nagashima et al. [12] infused the $A p o e^{-/-}$mice with $\mathrm{GIP}_{1-42}$ for 4 weeks and found that the plaques in the aorta in $A$ poe $e^{-/-}$mice were obviously smaller than the control group. Interestingly, some of the scientists found that GIP could decrease the mRNA expressions of VCAM-1 (vascular cell adhesion molecule-1), ICAM-1 (intercellular cell adhesion molecule-1), and PAI-1 (plasminogen activator inhibitor-1) and suppress the formation of foam cells.

GIP plays an important role in the regulation of glucose and lipid metabolism and protects vessels from atherosclerosis. The GIP-encoding gene located in ch17q21.3-q22 spans $10 \mathrm{~kb}$ containing 6 exons. The genetic variations in GIP gene may be predisposing risk factors for CAD especially in T2D patients through its gene expressions and/or molecular function impairment.

\section{Materials and Methods}

2.1. Subjects. The method to select enrolled patients was described by Wei et al. [13]. A total of 666 unrelated Chinese Han subjects with T2D were selected, among which 390 were CAD positive and 276 were CAD negative. At Peking University First Hospital and in this research as well, CAD positive indicates a stenosis $\geq 50 \%$ in at least one of the major coronary arteries or their main branches, while CAD negative represents the coronary stenosis of any main coronary arteries and main branches were $<50 \%$. The CAD results were confirmed by cardiac angiography or high specific spiral computer tomography (CT) scanning of coronary arteries.

Other known cardiovascular risk factors and demography data of all subjects were collected based on their medical records, including gender, age, body mass index (BMI), fasting plasma glucose (FPG), the history of dyslipidemia, hypertension (blood pressure $\geq 140 / 90 \mathrm{mmHg}$ or receiving any antihypertensive medications), and smoking status.

2.2. Single Nucleotide Polymorphism Genotyping. Genomic DNA of each sample was extracted from peripheral blood leukocytes using salting out procedure (Bioteke Whole Blood DNA Extraction Kit), as the methods described in Wei et al. [13].

Six exons were contained in GIP in ch17q21.3-q22. The total 2 haplotype-tagging SNPs at GIP locus from CHB data in HapMap Phase II database (http://www.hapmap.org) (R\#27, $\quad r^{2}<0.8, \quad$ MAF $\left.\geq 0.05\right)$ were selected, including rs2291725 (C>T) and rs8078510 (G>A). The 2 SNPs were genotyped using polymerase chain reaction-restriction fragment length polymorphism (PCR-RFLP), and the genotyping success rates were 95\%-100\%. Direct DNA sequencing was applied to further confirm the genotypes for each SNP for $5 \%$ of the cases and controls with the concordance rates between RFLP and DNA sequencing of $100 \%$.

2.3. Statistical Analysis. Both clinical and laboratorial data were reported by mean $\pm \mathrm{SD}$ or percentage. Hardy-
Weinberg equilibrium tests were carried out at each polymorphic locus to examine genotype distributions. Based on Haploview 4.2 (haplotypes are estimated using an accelerated EM algorithm), linkage disequilibrium (LD) and haplotype analysis were also conducted for all samples.

The SPSS statistical package (SPSS version 14.0, USA) was applied to perform statistical analyses of association of SNPs with the risk of CAD. Qualitative variables were compared via the $\chi^{2}$ test, while quantitative variables were compared via $t$-test on each independent sample or MannWhitney $U$ test. Multiple logistic regression analysis was conducted to study the correlation between CAD and genotypes, with necessary adjustment for other confounders of CAD like age, gender, BMI, and smoking status. As for the association between genotypes and outcomes, a descriptive measure was applied where $p<0.05$ was considered as statistical significance and odds ratios (ORs) were calculated with 95\% confidence intervals (CIs).

\section{Results}

The demographical data between CAD-positive and CADnegative groups were shown different in age, sex, smoking status, and lipid profile (Table 1). Hardy-Weinberg equilibrium tests for the 2 tag-SNPs are summarized in Table 2. Genotype distributions among the study population were in agreement with Hardy-Weinberg equilibrium at the 2 loci.

3.1. Polymorphism Distributions and Association Study. We analyzed the distribution of the 2 tag-SNPs in GIP gene in the study population. The allele A at rs8078510 was associated with decreased risk of $\mathrm{CAD} \quad(\mathrm{OR}=0.732,95 \%$ $\mathrm{CI}=0.544-0.985, p=0.039$ ) (Table 3 ). In additive inheritance model, the carriers of T/C in rs2291725 had a lower risk of $\mathrm{CAD}$ than the carriers of $\mathrm{C} / \mathrm{C}(\mathrm{OR}=0.592,95 \%$ $\mathrm{CI}=0.424-0.826, p=0.002)$, even after adjustment for the known CAD risk factors (gender, age, BMI, smoking status, dyslipidemia, hypertension history, and diabetic duration) $\left(\mathrm{OR}^{\prime}=0.603,95 \% \mathrm{CI}^{\prime}=0.392-0.930, p^{\prime}=0.022\right)$. As for rs8078510, the carriers of G/A had a lower risk of $\mathrm{CAD}$ than the carriers of $\mathrm{G} / \mathrm{G}(\mathrm{OR}=0.660,95 \% \mathrm{CI}=0.468$ $0.932, p=0.018)$, even after adjustment for of the known $\mathrm{CAD}$ risk factors $\left(\mathrm{OR}^{\prime}=0.567,95 \% \mathrm{CI}^{\prime}=0.364-0.883\right.$, $p^{\prime}=0.012$ ) (Table 4).

In dominant inheritance model, the carriers of $\mathrm{T} / \mathrm{T}$ or $\mathrm{T} / \mathrm{C}$ at rs2291725 had a lower risk of CAD ( $\mathrm{OR}=0.635,95 \%$ $\mathrm{CI}=0.463-0.872, p=0.005)$, even after adjustment for the known CAD risk factors $\left(\mathrm{OR}^{\prime}=0.769,95 \% \mathrm{CI}^{\prime}=0.626-\right.$ $\left.0.945, p^{\prime}=0.013\right)$, while the carriers of $\mathrm{G} / \mathrm{A}$ or $\mathrm{A} / \mathrm{A}$ at rs8078510 had a lower risk of CAD compared to those of G/ $\mathrm{G}\left(\mathrm{OR}=0.671,95 \% \mathrm{CI}=0.479-0.940, p=0.020 ; \mathrm{OR}^{\prime}=0.762\right.$, $95 \% \mathrm{CI}^{\prime}=0.612-0.949, p^{\prime}=0.015$ after adjustment) (Table 5).

3.2. Haplotype Analysis. Haplotypes were constructed using rs2291725 and rs8078510 depending on the physical position and the value of $\mathrm{D}^{\prime}\left(D^{\prime}>0.5\right)$ between the 2 SNPs in one block. Common haplotypes constructed by the 2 SNPs were CG, TG, TA, and CA (Table 6). And the haplotypes CG 
TABLE 1: The phenotypic characteristics of the study population.

\begin{tabular}{|c|c|c|c|}
\hline & $\begin{array}{l}\text { CAD positive } \\
\quad(n=390)\end{array}$ & $\begin{array}{l}\text { CAD negative } \\
\quad(n=276)\end{array}$ & $p$ \\
\hline Gender (M/F) & $257 / 133$ & $118 / 158$ & $<0.001$ \\
\hline Age (y) & $64(57-72)$ & $61(55-69)$ & 0.001 \\
\hline T2DM history (y) & $8(3-13)$ & $7(3-12)$ & 0.769 \\
\hline Hypertension history (\%) & 76.2 & 70.7 & 0.110 \\
\hline FPG (mmol/L) & $6.45(5.59-7.80)$ & $6.42(5.47-7.64)$ & 0.263 \\
\hline HbAlc (\%) & $6.8(6.3-7.8)$ & $6.7(6.1-7.5)$ & 0.080 \\
\hline $\mathrm{TG}(\mathrm{mmol} / \mathrm{L})$ & $1.39(0.96-1.93)$ & $1.40(0.97-2.03)$ & 0.615 \\
\hline $\mathrm{TC}(\mathrm{mmol} / \mathrm{L})$ & $4.00 \pm 1.04$ & $4.24 \pm 0.92$ & 0.004 \\
\hline LDL-c (mmol/L) & $2.26(1.79-2.91)$ & $2.45(1.91-2.94)$ & 0.071 \\
\hline HDL-c (mmol/L) & $0.95(0.80-1.10)$ & $1.03(0.86-1.23)$ & $<0.001$ \\
\hline BMI $\left(\mathrm{kg} / \mathrm{m}^{2}\right)$ & $26.39 \pm 3.37$ & $26.19 \pm 3.61$ & 0.472 \\
\hline Smoking history (\%) & 51.5 & 34.1 & $<0.001$ \\
\hline
\end{tabular}

TABLE 2: The Hardy-Weinberg equilibrium test.

\begin{tabular}{lccc}
\hline Gene & SNPs & $n$ & ${ }^{2}(p)$ \\
\hline GIP & rs2291725 & & \\
& $\mathrm{C} / \mathrm{C}$ & 102 & $3.113(0.078)$ \\
$\mathrm{C} / \mathrm{T}$ & 140 & \\
$\mathrm{~T} / \mathrm{T}$ & 30 & \\
& $\mathrm{rs} 8078510$ & & \\
$\mathrm{G} / \mathrm{G}$ & 174 & $2.993(0.084)$ \\
$\mathrm{G} / \mathrm{A}$ & 90 & \\
$\mathrm{~A} / \mathrm{A}$ & 5 & \\
\hline
\end{tabular}

and CA showed a significant association with CAD, the carriers of CG had a higher risk of CAD compared to noncarriers $(\mathrm{OR}=1.381,95 \% \mathrm{CI}=1.100-1.733, p=0.005)$, while the carriers of CA had a lower risk of CAD compared to noncarriers $(\mathrm{OR}=0.173,95 \% \mathrm{CI}=0.058-0.521, p<0.001)$.

3.3. BMI Subgroup Analysis. The genotype data were further analyzed after the subjects stratified by BMI. The individuals with the BMI of $24 \mathrm{~kg} / \mathrm{m}^{2}$ or above had an increased risk for CAD when they carried $\mathrm{C} / \mathrm{C}$ at $\mathrm{rs} 2291725\left(\mathrm{OR}^{\prime}=1.291\right.$, 95\% CI' $\left.=1.017-1.639, p^{\prime}=0.036\right)$ (Table 7).

3.4. Age Subgroup Analysis. The men aged $<55$ and women aged $<65$, while carrying allele $C$ at rs2291725 had a higher risk of $\mathrm{CAD}$ than noncarriers $(\mathrm{OR}=1.627,95 \% \mathrm{CI}=1.097$ $2.415, p=0.015$ ). Besides, out of the relatively young subjects, those carrying allele $\mathrm{G}$ at $\mathrm{rs} 8078510$ had a higher risk for CAD $(\mathrm{OR}=2.049,95 \% \mathrm{CI}=1.213-3.463, p=0.007)$, so $\mathrm{did}$ the carriers of $\mathrm{G} / \mathrm{G}$ than $\mathrm{A} / \mathrm{A}$ or $\mathrm{A} / \mathrm{G}(\mathrm{OR}=2.358,95 \%$ $\mathrm{CI}=1.304-4.266, p=0.004 ; \mathrm{OR}^{\prime}=1.589,95 \% \mathrm{CI}^{\prime}=1.071-$ $2.357, p^{\prime}=0.021$ after adjustment) (Tables 8 and 9 ).

3.5. Smoking Subgroup Analysis. Among the subjects who had ever smoked, the carriers of allele C at rs2291725 were more susceptible to CAD than the ones carrying allele $\mathrm{T}$ $(\mathrm{OR}=1.485,95 \% \mathrm{CI}=1.036-2.129, p=0.031)$, and those who carried genotype $\mathrm{C} / \mathrm{C}$ were also at high risk for $\mathrm{CAD}$ $\left(\mathrm{OR}=1.803,95 \% \mathrm{CI}=1.075-3.024, p=0.025 ; \mathrm{OR}^{\prime}=1.500\right.$, $95 \% \mathrm{CI}^{\prime}=1.052-2.140, p^{\prime}=0.025$ after adjustment); allele $\mathrm{G}$ at $\mathrm{rs} 8078510$ was associated with $\mathrm{CAD}$ risk $(\mathrm{OR}=1.695$, $95 \% \mathrm{CI}=1.080-2.660, p=0.021)$ (Tables 10 and 11 ).

3.6. Accumulative Risk Analysis. We took the risk genotype of rs2291725 (C/C) and rs8078510 (G/G) as CAD risk factors, along with other recognized CAD risk factors including age, sex (male $\geq 55 y$, female $\geq 65 y$ ), smoking, and $\mathrm{BMI} \geq 24 \mathrm{~kg} / \mathrm{m}^{2}$. After calculating the number of risk factors of each sample as accumulative risk score, we analyzed the association of accumulative risk score with CAD. Compared with T2D patients without any risk factors mentioned above, those who had 3 risk factors were at higher risk for CAD $(\mathrm{OR}=5.000,95 \% \mathrm{CI}=1.335-18.733$, $p=0.009)$. As for patients with 4 and 5 risk factors, their $\mathrm{CAD}$ risk increased even further $(\mathrm{OR}=7.800,95 \%$ $\mathrm{CI}=2.059-29.552, \quad p=0.001 \quad$ and $\quad \mathrm{OR}=11.026, \quad 95 \%$ $\mathrm{CI}=2.634-46.146, p<0.001$, resp.) (Table 12 ).

\section{Discussion}

GIP, a member of the incretin family, secreted from intestinal epithelial $\mathrm{K}$ cells, regulates glucose and lipid metabolism through binding to GIP receptors. Apart from that, GIP also has direct effects on cardiovascular system protection [14]. It could be hypothesized that the polymorphisms in the GIP gene may be associated with CAD, especially in type 2 diabetic populations.

In this study, we found that, in dominant inheritance model, the carriers of $\mathrm{T} / \mathrm{T}$ or $\mathrm{T} / \mathrm{C}$ of $\mathrm{rs} 2291725$ had lower $\mathrm{CAD}$ risk compared to $\mathrm{C} / \mathrm{C}$ carriers. At rs2291725 when allele $\mathrm{T}$ is replaced by allele $\mathrm{C}$, there will be a missense mutation, ser103gly, which may affect the structure and function of GIP. A recent GWAS (genome-wide association study) revealed that rs46522 was a CAD risky SNP [15]. Interestingly, rs46522 was at strong linkage disequilibrium 
TABLE 3: Association of allele frequencies at 2 SNPs with CAD in type 2 diabetic patients.

\begin{tabular}{ccccc}
\hline Gene & SNPs & CAD positive $n(\%)$ & CAD negative $n(\%)$ & OR (95\% CI) \\
\hline GIP & rs2291725 & $526(68.3)$ & $344(63.2)$ & \\
& C & $244(31.7)$ & $200(36.8)$ & $0.798(0.633-1.005)$ \\
& T & & & \\
& rs8078510 & $658(85.7)$ & $100(18.6)$ & 0.055 \\
G & $110(14.3)$ & $0.732(0.544-0.985)$ & 0.039 \\
\hline
\end{tabular}

TABLE 4: The association of SNPs with CAD risk in additive inheritance mode.

\begin{tabular}{|c|c|c|c|c|c|c|c|}
\hline Gene & SNPs genotype & CAD positive $n(\%)$ & CAD negative $n(\%)$ & OR $(95 \% \mathrm{CI})$ & $p$ & $\mathrm{OR}^{\prime}\left(95 \% \mathrm{CI}^{\prime}\right)$ & $p^{\prime}$ \\
\hline \multirow[t]{8}{*}{ GIP } & rs2291725 & & & & & & \\
\hline & $\mathrm{C} / \mathrm{C}$ & $187(48.6)$ & $102(37.5)$ & & & & \\
\hline & $\mathrm{C} / \mathrm{T}$ & $152(39.5)$ & $140(51.5)$ & $0.592(0.424-0.826)$ & 0.002 & $0.603(0.392-0.930)$ & 0.022 \\
\hline & $\mathrm{T} / \mathrm{T}$ & $46(11.9)$ & $30(11.0)$ & $0.836(0.498-1.406)$ & 0.500 & $0.709(0.502-1.001)$ & 0.051 \\
\hline & rs8078510 & & & & & & \\
\hline & $\mathrm{G} / \mathrm{G}$ & $281(73.2)$ & $174(64.7)$ & & & & \\
\hline & G/A & $96(25.0)$ & $90(33.5)$ & $0.660(0.468-0.932)$ & 0.018 & $0.567(0.364-0.883)$ & 0.012 \\
\hline & $\mathrm{A} / \mathrm{A}$ & $7(1.8)$ & $5(1.8)$ & $0.867(0.271-2.774)$ & 0.810 & $1.065(0.427-2.653)$ & 0.893 \\
\hline
\end{tabular}

$\mathrm{OR}^{\prime}, 95 \% \mathrm{CI}^{\prime}$, and $p^{\prime}$ were calculated by logistic regression analysis after adjustment for other known CAD risk factors (age, BMI, smoking status, dyslipidemia history, hypertension history, and diabetic duration).

TABLE 5: The association of SNPs with CAD risk in dominant inheritance mode.

\begin{tabular}{|c|c|c|c|c|c|c|c|}
\hline Gene & SNPs genotype & CAD positive $n(\%)$ & CAD negative $n(\%)$ & OR $(95 \%$ CI $)$ & $p$ & $\mathrm{OR}^{\prime}\left(95 \% \mathrm{CI}^{\prime}\right)$ & $p^{\prime}$ \\
\hline \multirow[t]{6}{*}{ GIP } & rs2291725 & & & & & & \\
\hline & $\mathrm{C} / \mathrm{C}$ & $187(48.6)$ & $102(37.5)$ & & & & \\
\hline & $\mathrm{C} / \mathrm{T}+\mathrm{T} / \mathrm{T}$ & $198(51.4)$ & $170(62.5)$ & $0.635(0.463-0.872)$ & 0.005 & $0.769(0.626-0.945)$ & 0.013 \\
\hline & rs 8078510 & & & & & & \\
\hline & $\mathrm{G} / \mathrm{G}$ & $281(73.2)$ & $174(64.7)$ & & & & \\
\hline & $\mathrm{G} / \mathrm{A}+\mathrm{A} / \mathrm{A}$ & $103(26.8)$ & $95(35.3)$ & $0.671(0.479-0.940)$ & 0.020 & $0.762(0.612-0.949)$ & 0.015 \\
\hline
\end{tabular}

$\mathrm{OR}^{\prime}, 95 \% \mathrm{CI}^{\prime}$, and $p^{\prime}$ were calculated by logistic regression analysis after adjustment for other known CAD risk factors (age, BMI, smoking status, dyslipidemia history, hypertension history, and diabetic duration).

TABLE 6: Association of the frequencies of common haplotypes with CAD.

\begin{tabular}{lccc}
\hline Haplotype (rs2291725 and rs8078510) & CAD positive (\%) & CAD negative (\%) & OR (95\% CI) \\
\hline CG & 67.8 & 60.3 & $1.381(1.100-1.733)$ \\
TG & 17.8 & 21.1 & $0.810(0.615-1.067)$ \\
TA & 13.9 & 15.8 & 0.133 \\
CA & 0.6 & 2.9 & $0.862(0.634-1.170)$ \\
\hline
\end{tabular}

TABLE 7: The association of SNPs with CAD risk in overweight/obesity subgroup in dominant inheritance mode.

\begin{tabular}{|c|c|c|c|c|c|c|c|}
\hline Gene & SNPs genotype & CAD positive $n(\%)$ & CAD negative $n(\%)$ & OR $(95 \%$ CI $)$ & $p$ & $\mathrm{OR}^{\prime}\left(95 \% \mathrm{CI}^{\prime}\right)$ & $p^{\prime}$ \\
\hline \multirow[t]{3}{*}{ GIP } & rs2291725 & & & & & & \\
\hline & $\mathrm{C} / \mathrm{C}$ & $142(47.8)$ & $83(40.5)$ & $1.347(0.939-1.930)$ & 0.105 & $1.291(1.017-1.639)$ & 0.036 \\
\hline & $\mathrm{C} / \mathrm{T}+\mathrm{T} / \mathrm{T}$ & $155(52.2)$ & $122(59.5)$ & & & & \\
\hline
\end{tabular}

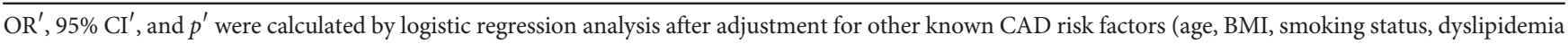
history, hypertension history, and diabetic duration). 
TABLE 8: Allele distributions of GIP SNPs in male $<55 \mathrm{y}$ and female $<65 \mathrm{y}$.

\begin{tabular}{ccccc}
\hline Gene & SNPs & CAD positive $n(\%)$ & CAD negative $n(\%)$ & OR (95\% CI) \\
\hline GIP & rs2291725 & & & \\
& C & $156(72.9)$ & $157(62.3)$ & $1.627(1.097-2.415)$ \\
& T & $58(27.1)$ & $95(37.7)$ & \\
& rs8078510 & & $197(79.4)$ & $2.049(1.213-3.463)$ \\
& G & $190(88.8)$ & $51(20.6)$ & 0.007 \\
& A & $24(11.2)$ & & \\
\hline
\end{tabular}

TABLE 9: Genotype distributions of GIP SNPs in male $<55 \mathrm{y}$ and female $<65 \mathrm{y}$ in dominant inheritance mode.

\begin{tabular}{|c|c|c|c|c|c|c|c|}
\hline Gene & SNPs genotype & CAD positive $n(\%)$ & CAD negative $n(\%)$ & OR (95\% CI) & $p$ & $\mathrm{OR}^{\prime}\left(95 \% \mathrm{CI}^{\prime}\right)$ & $p^{\prime}$ \\
\hline \multirow[t]{6}{*}{ GIP } & rs2291725 & & & & & & \\
\hline & $\mathrm{C} / \mathrm{C}$ & $55(51.4)$ & $44(34.9)$ & $1.971(1.164-3.339)$ & 0.011 & $1.346(0.958-1.892)$ & 0.087 \\
\hline & $\mathrm{C} / \mathrm{T}+\mathrm{T} / \mathrm{T}$ & $52(48.6)$ & $82(65.1)$ & & & & \\
\hline & rs8078510 & & & & & & \\
\hline & $\mathrm{G} / \mathrm{G}$ & $85(79.4)$ & $77(62.1)$ & $2.358(1.304-4.266)$ & 0.004 & $1.589(1.071-2.357)$ & 0.021 \\
\hline & $\mathrm{G} / \mathrm{A}+\mathrm{A} / \mathrm{A}$ & $22(20.6)$ & $47(37.9)$ & & & & \\
\hline
\end{tabular}

$\mathrm{OR}^{\prime}, 95 \% \mathrm{CI}^{\prime}$, and $p^{\prime}$ were calculated by logistic regression analysis after adjustment for other known CAD risk factors (age, BMI, smoking status, dyslipidemia history, hypertension history, and diabetic duration).

TABLE 10: Allele distributions of GIP SNPs in smoking patients.

\begin{tabular}{|c|c|c|c|c|c|}
\hline Gene & SNPs & CAD positive $n(\%)$ & CAD negative $n(\%)$ & OR $(95 \% \mathrm{CI})$ & $p$ \\
\hline \multirow[t]{6}{*}{ GIP } & rs2291725 & & & & \\
\hline & C & $267(67.8)$ & $109(58.6)$ & $1.485(1.036-2.129)$ & 0.031 \\
\hline & $\mathrm{T}$ & $127(32.2)$ & $77(41.4)$ & & \\
\hline & rs8078510 & & & & \\
\hline & G & $345(86.3)$ & $148(78.7)$ & $1.695(1.080-2.660)$ & 0.021 \\
\hline & A & $55(13.8)$ & $40(21.3)$ & & \\
\hline
\end{tabular}

TABLE 11: Genotype distributions of rs2291725 in smoking patients in dominant inheritance mode.

\begin{tabular}{|c|c|c|c|c|c|c|c|}
\hline Gene & SNPs genotype & CAD positive $n(\%)$ & CAD negative $n(\%)$ & OR $(95 \% \mathrm{CI})$ & $p$ & $\mathrm{OR}^{\prime}\left(95 \% \mathrm{CI}^{\prime}\right)$ & $p^{\prime}$ \\
\hline \multirow[t]{3}{*}{ GIP } & rs2291725 & & & & & & \\
\hline & $\mathrm{C} / \mathrm{C}$ & $91(46.2)$ & $30(32.3)$ & $1.803(1.075-3.024)$ & 0.025 & $1.500(1.052-2.140)$ & 0.025 \\
\hline & $\mathrm{C} / \mathrm{T}+\mathrm{T} / \mathrm{T}$ & $106(53.8)$ & $63(67.7)$ & & & & \\
\hline
\end{tabular}

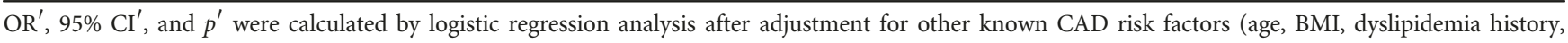
hypertension history, and diabetic duration).

TABLE 12: The association of accumulative risk score with CAD risk in T2D patients.

\begin{tabular}{|c|c|c|c|c|}
\hline Risk factors & CAD positive $n(\%)$ & CAD negative $n(\%)$ & OR (95\% CI) & $p$ \\
\hline 0 & $3(0.7)$ & $10(3.6)$ & 1 & 1 \\
\hline 1 & $28(7.2)$ & $42(15.2)$ & $2.222(0.561-8.798)$ & 0.247 \\
\hline 2 & $79(20.3)$ & $81(29.4)$ & $3.251(0.862-12.254)$ & 0.068 \\
\hline 3 & $120(30.8)$ & $80(29.0)$ & $5.000(1.335-18.733)$ & 0.009 \\
\hline 4 & $117(30.0)$ & $50(18.1)$ & $7.800(2.059-29.552)$ & 0.001 \\
\hline 5 & $43(11.0)$ & $13(4.7)$ & $11.026(2.634-46.146)$ & $<0.001$ \\
\hline
\end{tabular}


with rs2291725 in the Chinese Han population, which could be interpreted that the rs 2291725 in GIP gene could affect genetic susceptibility to CAD in the population. And in overweight/obese patients, the homozygotes of CC at rs2291725 had significantly higher risk for CAD compared to noncarriers, which indicated that to control body weight would be a much more important strategy for the genetic susceptible individuals.

Rs8078510, the other undocumented SNP, was also found associated with CAD risk in type 2 diabetic patients in the Chinese Han population. Patients carrying minor allele A exhibited an almost one-third lower risk of CAD than noncarriers. Rs 8078510 is located in the first intron of GIP gene, close to $5^{\prime}$ region, which may have an effect on the transcription and translation of genes [16]. Besides, it may be at strong linkage disequilibrium with a CAD risky gene as a genetic marker.

Furthermore, the carriers of haplotype CA of rs2291725 and rs8078510 had a four-fifth lower risk of CAD compared to noncarriers $(95 \% \mathrm{CI}=0.058-0.521, p<0.001)$. Importantly, the carriers of the haplotype CG constructed by the 2 risky alleles, respectively, at rs2291725 and rs8078510 even had a $40 \%$ higher risk of CAD even compared to the any other noncarriers $(95 \% \mathrm{CI}=1.100-1.733, p=0.005)$. Both rs2291725 and rs8078510 could be better as genetic dominants to screen individuals at high risk for CAD than only rs 2291725 .

The early-onset CAD is a threatening social-economic issue. In the study, we found that rs2291725 and rs8078510 in association with CAD especially played an important role in the younger patients (age $<55$ in male and age $<65$ in female) (OR 1.6-2.0, $p<0.05)$. It indicated that the SNPs might be used to screen the subjects at high risk for premature coronary artery disease.

GIP is related with both diabetes and obesity [17]. Recent study proved that GIP regulated directly on the metabolism in adipocytes through a naturally occurring variant of GIPR (E354Q) [18]. In our study, overweight and obesity subjects had an increased risk for CAD when they carried $\mathrm{C} / \mathrm{C}$ at $\mathrm{rs} 2291725\left(p^{\prime}=0.036\right)$, which was in accordance with previous studies.

Unexpectedly, while regarding rs2291725 and rs8078510 as genetic risk factors for CAD together with age, sex, BMI, and smoking, the more the number of risk factors that the individuals were carrying, the bigger the odds ratios were for CAD risk $(p<0.05)$. It could be interpreted clinically that it should be rather more important to screen out the subjects at high risk of CAD by the genetic factors in combination with regular factors and earlier intervene those patients on controllable risk factors.

In general, the study showed that the rs2291725 and rs 8078510 could be taken as genetic risk factors for CAD along with traditional ones as sex, BMI, smoking, and so on, at least in the patients with type 2 diabetes.

There were some limitations in our study. The sample size was relatively small and the clinical features were not perfectly matched between the case and control groups, which might incur the possibility to introduce bias. Further functional and prospective studies on the GIP gene are required before GIP polymorphisms could be used as predictors of CAD risk in patients with type 2 diabetes in the Chinese Han population.

\section{Abbreviations}

GIP: $\quad$ Glucose-dependent insulinotropic polypeptide

DPP-4: Dipeptidyl peptidase-4

T2D: $\quad$ Type 2 diabetes

CAD: $\quad$ Coronary artery disease

CT: $\quad$ Computer tomography

SNPs: $\quad$ Single nucleotide polymorphisms

PCR: Polymerase chain reaction

RFLP: Restriction fragment length polymorphism

BMI: $\quad$ Body mass index

FPG: $\quad$ Fasting plasma glucose

LD: $\quad$ Linkage disequilibrium

ORs: $\quad$ Odds ratios

CIs: $\quad$ Confidence intervals

GLUT-1: Glucose transporter-1

VCAM-1: Vascular cell adhesion molecule-1

ICAM-1: Intercellular cell adhesion molecule-1

PAI-1: Plasminogen activator inhibitor-1

GWAS: Genome-wide association study.

\section{Conflicts of Interest}

The authors declare that they have no conflicts of interest.

\section{Authors' Contributions}

Jia Huang researched data and wrote manuscript. Xiaowei Ma edited the manuscript. Difei Lu, Ran Lu, Jianwei Zhang, Nan $\mathrm{Gu}$, Hong Zhang, and Jianping Li researched data and contributed to discussion. Xiaohui Guo reviewed the manuscript and contributed to discussion.

\section{Acknowledgments}

The authors are very grateful to the staff for the excellent contributions to the work from Department of Cardiology, Radiology and Statistics and so on in Peking University First Hospital, for helping data collection. The authors also want to show our gratitude to all the patients involved in this study.

\section{References}

[1] Y. Wang, C. Montrose-Rafizadeh, L. Adams, M. Raygada, O. Nadiv, and J. M. Egan, "GIP regulates glucose transporters, hexokinases, and glucose-induced insulin secretion in RIN 1046-38 cells," Molecular and Cellular Endocrinology, vol. 116, no. 1, pp. 81-87, 1996.

[2] L. L. Baggio and D. J. Drucker, "Biology of incretins: GLP-1 and GIP," Gastroenterology, vol. 132, no. 6, pp. 2131-2157, 2007.

[3] B. N. Friedrichsen, N. Neubauer, Y. C. Lee et al., "Stimulation of pancreatic beta-cell replication by incretins involves transcriptional induction of cyclin D1 via multiple signalling 
pathways," The Journal of Endocrinology, vol. 188, no. 3, pp. 481-492, 2006.

[4] N. Irwin, G. C. Clarke, B. D. Green et al., "Evaluation of the antidiabetic activity of DPP IV resistant N-terminally modified versus mid-chain acylated analogues of glucosedependent insulinotropic polypeptide," Biochemical Pharmacology, vol. 72, no. 6, pp. 719-728, 2006.

[5] J. A. Ehses, V. R. Casilla, T. Doty et al., "Glucose-dependent insulinotropic polypeptide promotes $\beta$-(INS-1) cell survival via cyclic adenosine monophosphate-mediated caspase-3 inhibition and regulation of $\mathrm{p} 38$ mitogen-activated protein kinase," Endocrinology, vol. 144, no. 10, pp. 4433-4445, 2003.

[6] A. Trumper, K. Trumper, and D. Horsch, "Mechanisms of mitogenic and anti-apoptotic signaling by glucose-dependent insulinotropic polypeptide in beta (INS-1)-cells," Journal of Endocrinology, vol. 174, no. 2, pp. 233-246, 2002.

[7] A. Trümper, K. Trümper, H. Trusheim, R. Arnold, B. Göke, and D. Hörsch, "Glucose-dependent insulinotropic polypeptide is a growth factor for beta (INS-1) cells by pleiotropic signaling," Molecular Endocrinology, vol. 15, no. 9, pp. 15591570, 2001.

[8] A. Maida, T. Hansotia, C. Longuet, Y. Seino, and D. J. Drucker, "Differential importance of glucose-dependent insulinotropic polypeptide vs glucagon-like peptide 1 receptor signaling for beta cell survival in mice," Gastroenterology, vol. 137, no. 6, pp. 2146-2157, 2009.

[9] M. Christensen, L. Vedtofte, J. J. Holst, T. Vilsboll, and F. K. Knop, "Glucose-dependent insulinotropic polypeptide: a bifunctional glucose-dependent regulator of glucagon and insulin secretion in humans," Diabetes, vol. 60, no. 12, pp. 3103-3109, 2011.

[10] M. Christensen, S. Calanna, A. H. Sparre-Ulrich et al., "Glucose-dependent insulinotropic polypeptide augments glucagon responses to hypoglycemia in type 1 diabetes," Diabetes, vol. 64, no. 1, pp. 72-78, 2014.

[11] M. A. Nauck, M. M. Heimesaat, C. Orskov, J. J. Holst, R. Ebert, and W. Creutzfeldt, "Preserved incretin activity of glucagonlike peptide 1 [7-36 amide] but not of synthetic human gastric inhibitory polypeptide in patients with type-2 diabetes mellitus," Journal of Clinical Investigation, vol. 91, no. 1, pp. 301307, 1993.

[12] M. Nagashima, T. Watanabe, M. Terasaki et al., "Native incretins prevent the development of atherosclerotic lesions in apolipoprotein E knockout mice," Diabetologia, vol. 54, no. 10, pp. 2649-2659, 2011.

[13] X. Wei, X. Ma, R. Lu et al., "Genetic variants in PCSK1 gene are associated with the risk of coronary artery disease in type 2 diabetes in a Chinese Han population: a case control study," PLoS One, vol. 9, no. 1, article e87168, 2014.

[14] J. Zhong, X. Rao, and S. Rajagopalan, “An emerging role of dipeptidyl peptidase 4 (DPP4) beyond glucose control: potential implications in cardiovascular disease," Atherosclerosis, vol. 226, no. 2, pp. 305-314, 2013.

[15] N. N. Mehta, "Large-scale association analysis identifies 13 new susceptibility loci for coronary artery disease," Circulation: Cardiovascular Genetics, vol. 4, no. 3, pp. 327-329, 2011.

[16] L. J. Baier, P. A. Permana, X. Yang et al., “A calpain-10 gene polymorphism is associated with reduced muscle mRNA levels and insulin resistance," Journal of Clinical Investigation, vol. 106, no. 7, pp. R69-R73, 2000.
[17] X. M. Wang, Y. J. Yang, and Y. J. Wu, "The emerging role of dipeptidyl peptidase-4 inhibitors in cardiovascular protection: current position and perspectives," Cardiovascular Drugs and Therapy, vol. 27, no. 4, pp. 297-307, 2013.

[18] S. Mohammad, R. T. Patel, J. Bruno, M. S. Panhwar, J. Wen, and T. E. McGraw, "A naturally occurring GIP receptor variant undergoes enhanced agonist-induced desensitization, which impairs GIP control of adipose insulin sensitivity," Molecular and Cellular Biology, vol. 34, no. 19, pp. 36183629, 2014. 


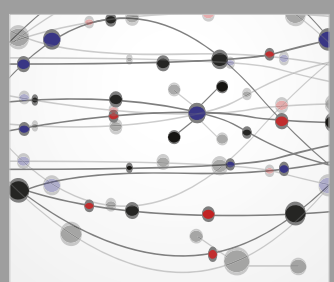

The Scientific World Journal
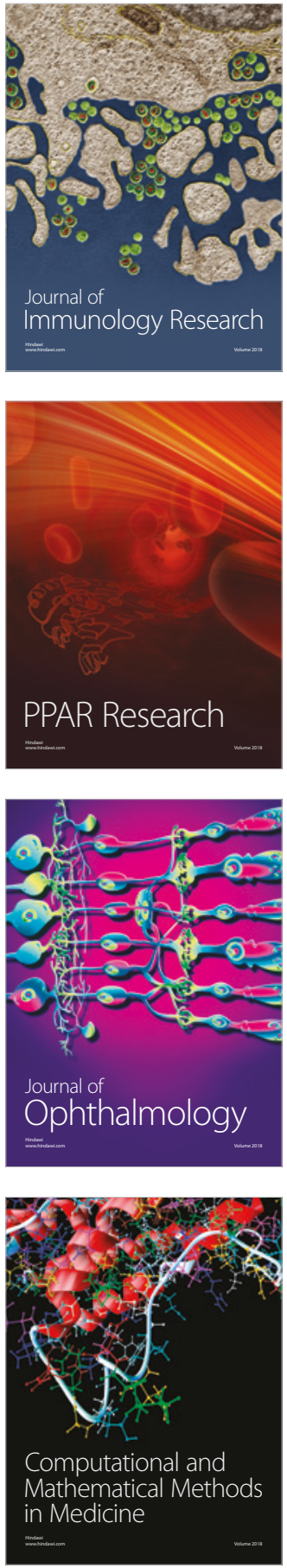

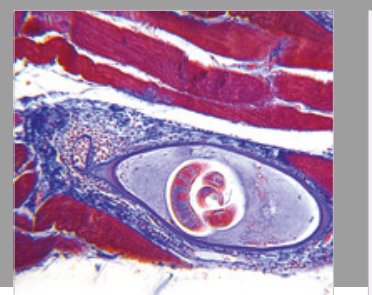

Gastroenterology Research and Practice

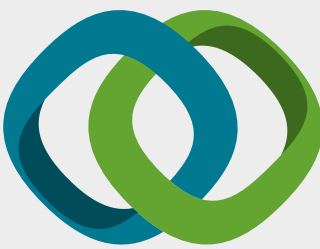

\section{Hindawi}

Submit your manuscripts at

www.hindawi.com
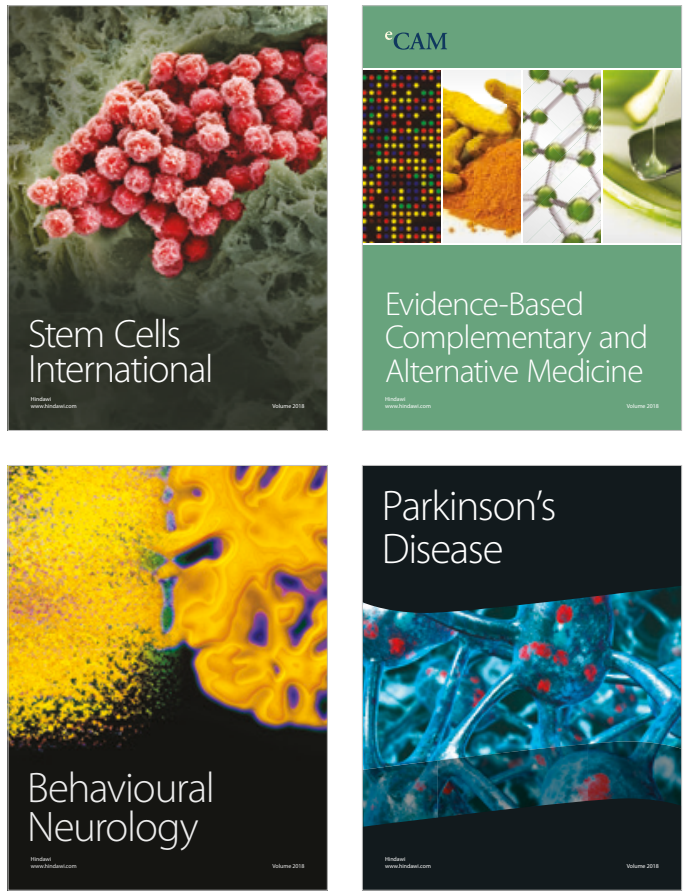

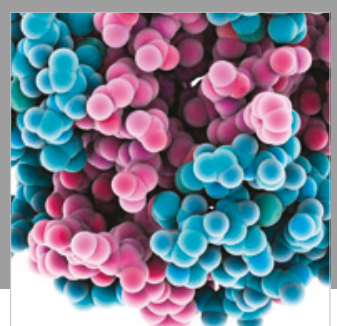

ournal of

Diabetes Research

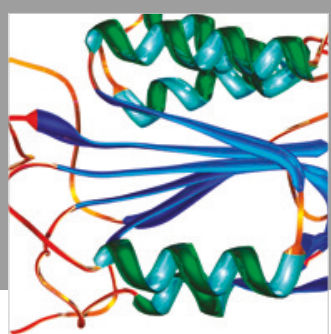

Disease Markers
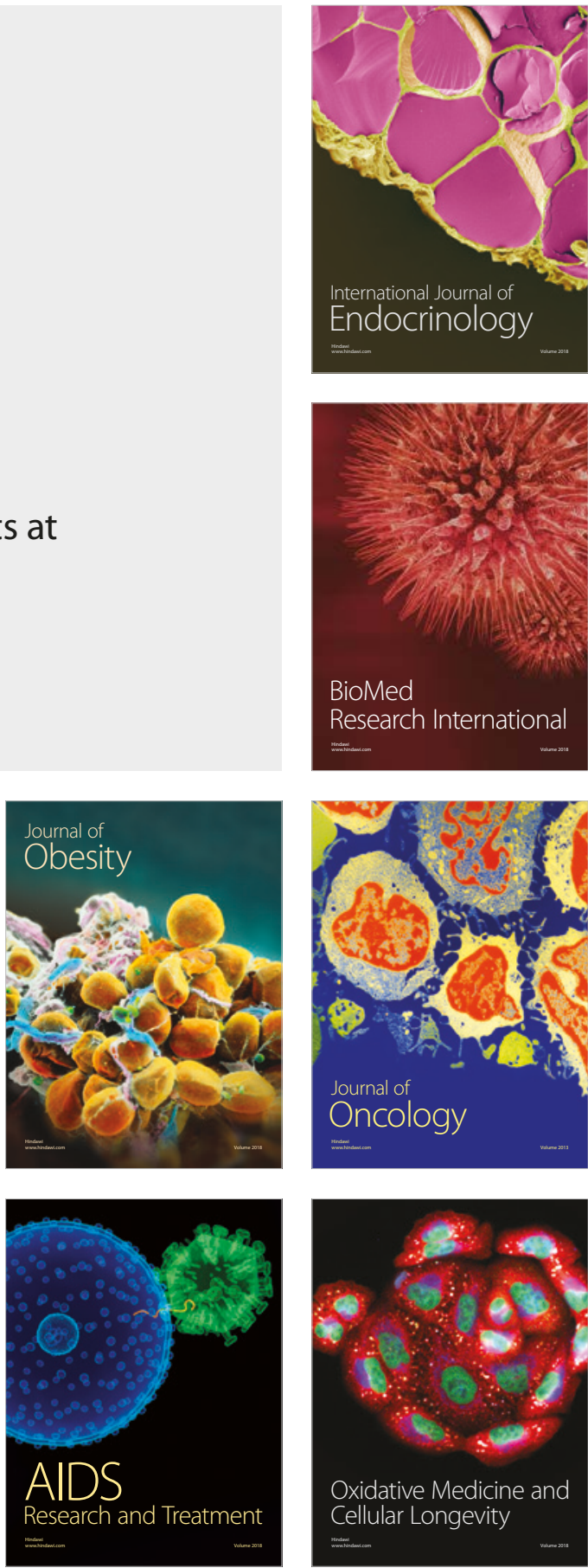